\title{
A Human Perspective of Contractor Prequalification
}

Bassam Michael Baroudi (School of Natural and Built Environments, University of South Australia)

Mike Metcalfe (School of Management, University of South Australia, Australia)

\begin{abstract}
The contractor prequalification topic has had much written on it over the last two decades. In the past it has been primarily viewed in terms of the appropriate selection of contractors for construction projects. There has been extensive research interest into the functional and process driven aspects of contractor prequalification. However, there has been little research taking a more holistic view of contractor prequalification in terms of the human aspects that surround it. Hence, gaining a wider appreciation on how prequalification systems affect the major stakeholders seems warranted. The use of soft systems thinking allowed for an indepth and contextual analysis of prequalification issues. This necessitated unstructured indepth interviews to be carried out with senior industry practitioners. Sifting through their respective experiences allowed for an alternative view of contractor prequalification systems, a very human perspective to emerge. The research suggests that viewing prequalification systems from a human perspective provides a fuller picture of their true benefits and limitations. This could then translate into better prequalification design.
\end{abstract}

Keywords: Prequalification, Human aspects, Soft systems

\section{Introduction}

Contractor prequalification is a common client prerequisite for construction companies. Russell and Skibiniewski (1988) define prequalification as involving the use of criteria by a client to screen contractors in order to determine capabilities in respect to performing building works. Sir Michael Latham's (1994) review of the UK building industry presented a number of issues in respect to improving procurement practices via prequalification systems. The Construction Industry Development Agency's (CIDA, 1994) work in Australia also contributed to prequalification systems development. Many have since seen the need for appropriate prequalification systems. For example, Prichard (2000) offers that prequalification systems allow clients and contractors to concentrate on the tendering process rather than be weighed down by issues of suitability and competency. It seems that prequalification systems have constantly advanced as clients seek to reduce their construction project risk. However, previous research has tended to focus more on process than people. This research serves to redress this situation.

Cheng and Li (2004) suggest that without a proper contractor selection process project performances will be affected. As such, accurate assessments are needed to evaluate contractor attributes against client requirements. However, Singh and Tiong (2005) contend that selecting contractors involves multi-criteria decision making which is influenced by human subjectivity and uncertainty. Furthermore, El-Sawalhi, Eaton, and Rustom (2007) suggest that people often use past experiences within their reasoning and problem solving. Sonmez, Holt, Yang and Graham (2002) add that humans are not machines and therefore quite often make intuitive decisions. They also suggest that people prefer to offer opinion in linguistic rather than numerical terms which creates ambiguity in decision making. Nga and Luub (2008) put forth that decision makers use intuition, experience or predictive judgment in relation to selections. Hence, people in the system can possibly be affected by erroneous assumptions and bias. $\mathrm{Ng}$ (2001) suggests that experiential human judgment is relied on in prequalification systems due to the difficulty and cost in obtaining and assessing contractor information. Therefore prequalifiers need to have the appropriate knowledge and experience to assess this information. 
Prequalification is often viewed in client terms. However, it would be worthwhile for clients to consider the viewpoints of other stakeholders. Jennings and Holt (1998), Minchin and Smith (2001) and Mills (2005) research moved away from focusing on client perspectives without acknowledging contractor sentiment. For example, Mills (2005) found that the perceived importance of various selection criteria between client and contractor differs greatly. Furthermore, $\mathrm{Ng}$, Skitmore and Smith (1999) found that various consultants' perceptions of which selection criteria were important differed significantly to the client and each other. As such, industry stakeholders were shown to think differently in regard to the importance of various selection criteria. This diversity of thought should be appreciated. It also suggests that industry people emanating from different disciplines are possibly biased towards their own objectives. Broader stakeholder involvement allows for a greater understanding of prequalification systems and how they affect people.

Prequalification systems typically use many types of criteria to assess contractor suitability. Palaneeswaran and Kumaraswamy's (2000) "RRC attributes", representing responsiveness, responsibility and competency, were designed as initial filtering criteria and touched on some of the more human aspects. Also, Palaneeswaran, $\mathrm{Ng}$ and Kumaraswamy (2006) found that Hong Kong public clients used criteria such as management capability, organisation and communication. Pongpeng and Liston (2003) identified technical ability criteria as carrying a high degree of importance and Lam, Hu and $\mathrm{Ng}$ (2005) found that a contractor's technical approach was closely related to the degree of innovation displayed during construction. Hence, a contractor's construction knowledge not only gives a client confidence in their capability but also in their capacity to suggest new ideas adding greater value to a project. Furthermore, this could relieve the client and design team of cumbersome decision making relating to technical issues on site. Ogunsemi (2006) found that the amount of contractor's work to be subcontracted out was an important selection criterion for clients. This indicates a growing realisation that prequalified contractors are only as good as their subordinate contractors.

Topcu (2004) found that UK government authorities rated selection criteria highlighting poor business dealings by contractors quite highly. The criteria in relation to fraudulent action, previous disbarment and contract failure all featured as very important. Furthermore, Minchin and Smith (2001) offer integrity criteria which relates to whether company officials have any convictions in respect to their business activities. They described this as a "disqualification" factor. Al-Harbi (2001) adds that criteria discovering unethical techniques are grounds for instant elimination from assessments. Lo, Krizek and Hadavi (1999) identified a number of problems that inadequately designed prequalification systems create. These included inappropriate behaviour via possible collusion and improper practices. These types of issues give the prequalification environment another dimension albeit on the negative side of human actions.

Prequalification systems can affect competition in the marketplace. Li, Foulger, and Phillips (2008) suggest that prequalification can limit the number of available tenderers creating reduced competitive behaviour from those invited to tender. Ngai, Drew, Lo and Skitmore (2002) say the two prime factors affecting the degree of competition are the number of contractors able to tender a project and market conditions at the time. Hence, prequalification systems need to appeal to capable contractors particularly in boom times. Jennings and Holt's (1998) research uncovered that larger contractors felt that prequalification systems with stringent multi-criteria selection decision making improves their chances of winning contracts. However they did also find that contractors are generally dissatisfied with prequalification possibly leading to Minchin and Smith (2001) assertion that there are good contractors who elect not to participate.

Wong (2004) points to the degree of sophistication of some assessment methods make them difficult for client use. Furthermore, Minchin and Smith (2001) contend that a problem 
with prequalification is that it adds to client and contractor workloads. In current times where more outputs are increasingly sought from fewer resources this becomes an issue. Mangitung and Emsley (2002) add that there is a need to reduce repetition, duplication and subsequent wasted resources brought about by industry prequalifications. They suggest centralisation of prequalification systems through a third party as a possible solution for contractor assessments. Palaneeswaran and Kumaraswamy (2005) found that designer/builder prequalification systems face difficulties in various areas including those of transparency and non standard practices. Ultimately, it would seem that prequalification systems need to fulfil their objectives whilst being non burdensome and fair on the people involved.

The rationale behind contractor prequalification appears valid however the above suggests that many experts believe that prequalification systems still harbour significant problems. Furthermore, Holt (2010) points out that during the last two decades research into contractor selection has focused more on decisional processes and criteria. Thus, a more holistic soft systems approach that takes a broader human perspective of prequalification could provide new ideas for prequalification design.

\section{Research Methodology}

In this research, pragmatic or soft systems thinking is proposed for use as the interpretation applied to prequalification. Checkland (2000) says that systems thinking can be a quantitative, positive or interpretive method. In this research, it is intended to be used in a qualitative and interpretive manner; as a thinking tool. The reason systems thinking is considered a suitable means of interpretation is mainly because of the researchers' interest in the perceived relationships or interactions between prequalification and people within the construction industry. Systems thinking is about the relationship between elements. Moreover, systems thinking presents itself as a way of thinking more holistically about a problem situation. This was the intent of this research. System approaches allow complex problems to be viewed in a more holistic fashion allowing one to examine the relationships between elements. Daellenbach (2003) discusses how these approaches have the ability to examine the greater system or focus in on a particular subsystem. Metcalfe (2006) suggests that systems thinking can help change the way that people think about issues by providing different dimensions to analyse situations.

Systems approaches allow observers to determine where the boundaries are drawn and what elements reside within a system as compared to what elements reside outside a system, i.e. the environment. Soft systems approaches allow for a more flexible and open interpretation of events. Schoderbek, Schoderbek and Kefalas (1990) explains how open systems can look at importing inputs from the environment so as to convert them into useful outputs. This is done via the transformation processes that serve these systems. Zulauf (2004) suggests that systems thinking allows people to concentrate on organisational dynamics rather than just focus in on particular situations. By considering the interrelationships (or connectivities) and thinking cross-functionally better results may be derived. She contends that one can increase their leverage by taking a strategic view of the situation prior to attacking the fundamental issues.

\section{Research Technique}

This research has chosen a qualitative interpretive method. Flick, von Kardorff and Ines (2004) contend that qualitative techniques generate knowledge such as that held by experts. Hence, the research questions will ask construction industry experts (i.e. clients, contractors and consultants) to convey their thoughts on prequalification systems. It was thought that not much would be achieved by attempting to quantify or average the collected data. This is because deeper human insights and alternative possibilities were being sought. Moore (2000) points out, the use of qualitative research can lead to deeper understandings of 
issues and their causes. Since this research is seeking a more holistic human view of prequalification, not a reductionist analytical one, a qualitative method was adopted.

The use of in-depth semi-structured interviews was adopted as the primary tool for the research. Such methods are seen as providing a rich source of information from experts. Skinner, Tagg and Holloway (2000) argue that research involving management issues can be difficult as the area can be both complex and messy. They contend that the use of qualitative research in these situations offers a richness and depth of understanding that quantitative methods fail to deliver. Fontana and Frey (2003) view the interviewing method as something that creates active interactions between two or more people towards "negotiated contextually based results". Bouma and Ling (2004) see in-depth interviews as allowing the participant to express their thoughts or the way they feel. They also argue that it gives participants the ability to give their own perspectives on what they believe to be important. Wright (1996) found in-depth interviewing techniques particularly useful on senior managers. He also contends that techniques which are "less directive" or semi-structured allow interviewees to apply their expertise as well as provide their attitudes, needs and ideas. This will assist in uncovering broader thought on prequalification issues. Hickey and Davis (2003) contend that in-depth interviews provide an understanding of people's behaviour as well as giving some context to situations. Further to this, they say that semistructured interviews also allow interviewees to suggest reasons behind particular forms of behaviour. In-depth interviewing might thus be considered to provide for a greater appreciation of situations than other alternative research methods.

\section{Interview Survey Sample}

A broad range of construction industry practitioners were selected for interviewing. They came from both the public and private sectors within the state of South Australia. The interviewees included clients, contractors and consultants. These were industry practitioners coming from both public and private organisations. They included senior personnel from government agencies, corporations, contractors, project management consultancies and architectural firms. Care was taken to ensure that all participants were highly experienced with prequalification systems and their operation. Twenty five prospective interviewees were invited to participate, twenty three accepted. Note that formal university ethics approval was required prior to approaching interviewees. The time spent with interviewees ranged between one and two hours each with this amount of time deemed sufficient to discuss relevant issues. Ticehurst and Veal (2000) suggest that in depth interviews should typically take at least a half an hour and can often take several hours. Flick et al (2004) point out interviewers should be aware that expert interviewees can be under intense time pressures. Thus it was thought that any more than two hours would overly impose on participants' time. Note that whilst some questions related to subcontractors these stakeholders were not included in the interviewing process as this was considered outside the scope of the study.

Participant information was gathered via a digital recorder set up at the commencement of each interview. Consent was gained prior to the use of the recorder. Notes were also taken during interviews to highlight points of interest. The key points were tabulated after each interview. The tabulated information was collated into common themes with participant identifications noted as applicable. The recorded information was professionally transcribed into a typed format. This provided a large volume of information for assessment. A combination of scrutinising the tabulated key points and the interview transcriptions extracted the required information.

\section{Results and Discussion}

The research uncovered many important alternative perspectives of prequalification. The findings have been grouped below under the areas of Relationships and Communications, Equity and Fairness, Skills Development and Professionalism, and Creativity and Innovation.

Baroudi, B M and Metcalfe, M (2011) 'A human perspective of contractor prequalification', Australasian Journal of Construction Economics and Building, 11 (2) 60-70 
These groupings could be thought of as alternative systems within the prequalification environment. This is because they contain perspectives that are different to the more prevalent conceptions of prequalification. The following results and discussions are derived from the in-depth conversations with interviewees.

\section{Relationships and Communications}

The issues of prequalification relationships and communications were quite prominent in the discussions. The common view was that clients wanted to develop good relationships with contractors and their teams. The same was said back by contractors. Prequalification was said to open up a forum to build such relationships. This in turn opens the way for effective communications between the various people involved. A prequalifier from a major public client had a very positive view on their relationships describing their contractor base as "our family of contractors". The idea of relationship building via prequalification does not feature in previous literature. Better client contractor relationships can only enhance procurement and subsequent processes. The same prequalifier also said that prequalification assists in keeping their contractor base well informed. Their view was that a prequalification register allowed them to do that by creating a target group to aim at. This form of well directed communications creates positive outputs for all concerned and could possibly alleviate contractor misconceptions or fears that commonly arise in project procurement. While this would seem valuable it may need further attention as contractor opinion tended to lean towards communications being inadequate.

The value of fostering good relationships was seen to extend outwards in many ways. It was said that prequalification encouraged contractors to not see each project or contract in isolation. In other words when a project ends the client's relationship with the contractor doesn't end. Being connected to the prequalification environment maintains this bonding relationship. Such a situation is thought to derive possible benefits such as improved communications, greater transparency and reduced adversarial behaviour. For example, a public sector client put forth an example of a project not performing as well financially as expected by the contractor. Having a relationship bonded by prequalification may have the contractor thinking twice before approaching the client for extra money via various contractual means. It was said the contractor would think "we're going to grow with them; we're not going to lose out." So in this case the client will not have to defend claims for extra payment. Hence, prequalification possibly encourages contractors to take a longer term view of their contracting relationships and therefore modify their behaviour.

Other ramifications for prequalification relationships appear to exist within contractor suspensions or disqualifications. A prequalifier from a major public housing department pointed out "I've always said you can't improve a builder unless he's working with you." His thinking was that suspensions or disqualifications do not improve behaviour in any case as the people involved are not in the learning environment to modify their behaviour. All that is being done is isolating people and organisations, which is punishment. This would not seem to be the right approach to improve the client's contractor base and associated relationships. The authors suggest that a better way forward would be to provide effective and timely feedback communications to these contractors. Government prequalifiers particularly commented that they offered feedback to improve future contractor performances. It is thought moving away from penalising contractors creates a better environment for solid relations. Furthermore in smaller marketplaces, keeping as many contractors as possible prequalified would seem essential to competition and resourcing projects.

A prequalifier working with a major public client said that they frequently engage with industry bodies to gauge the feelings of prequalification stakeholders. This form of engagement was described as providing one of their main feedback mechanisms. It was said that by maintaining these forms of liaisons clients and their prequalifiers can quickly pick up if there are grumblings within the construction community. It does appear that there is a

Baroudi, B M and Metcalfe, M (2011) 'A human perspective of contractor prequalification', Australasian Journal of Construction Economics and Building, 11 (2) 60-70 
genuine resolve to build stronger industry relationships with prequalification being a significant factor.

\section{Equity and Fairness}

Whilst the foundations of prequalification are based within suitable contractor selection it could be said that there was also a systems purpose to create just and equitable outputs for those who participate. Many of those interviewed talked of prequalification as providing a "level playing field." The importance of this issue within our research sample seemed to be much greater than that reflected in previous research. However, it should be noted that this feature did not come without its own problems.

Contractors remarked on the further need for transparency within formalised assessment processes. They felt that they were possibly not getting adequate consideration or at least not being informed appropriately. As one contractor commented "oh, it's smoke and mirrors and they probably won't tell you because they don't want that in the public domain so no one can challenge it." It was openly admitted by one prequalifier that scores awarded when judging contractors are generally made on "gut feelings" but having a panel of judges made for a reasonable consensus. Furthermore, another prequalifier indicated that the submitted contractor information itself is improving but the bigger concern is how this data is interpreted and the emphasis that can be drawn from that. The issue of subjectivity in decision making is well covered in past literature. However, it tends to lean towards the difficulty in selecting the most suitable contractor rather than how to foster equitable outcomes. This could be explained by the client being more concerned with selecting an appropriate contractor than fairness within the system. Another comment from a private sector project management consultant involved in prequalification assessments indicated that they had considerable latitude to exercise decisions that they would not be held accountable for later. The findings do raise some doubts in respect to the fairness of prequalification assessments on contracting people.

A negative output of prequalification systems was found to lie in the perception of contractor victimisation. That is some contractors felt that they were being victimised by the prequalification process. A prequalifier with a public client said that some people think that they have done a good job within their prequalification application via the information they had provided. However, these contractors have to be told that their credentials are not as strong as they would like to think. Hence, this type of outcome produces resentment with applicants expressing their bitterness. In fact, prequalifiers themselves held fears that disgruntled contractors would go over their heads, in some cases as far up as the responsible government minister. These types of human issues seem very novel in light of past research.

One contractor questioned prequalification's fairness when many of the softer human attributes were to a large degree missing from standard selection criteria. He mentioned the aspects of contractor honesty, integrity, and fairness as not getting adequate consideration for selection on forthcoming projects. The literature did report on some forms on these criteria although that was more about disadvantaging poor contractors than rewarding good contractors via these criteria. A public sector respondent possibly points to why industry does not pay more attention to contractors' personal qualities. He commented that the construction industry is dominated by people who have a technical objective background. Hence, some of the softer, more qualitative sociological concepts do not sit very easily in the context of this environment. Further research that addresses contractor personal qualities would seem worthwhile. 


\section{Skills Development and Professionalism}

The discussions revealed that prequalifiers, particularly those in the public sector, had a strong view of having to balance short term project requirements and long-term industry needs. The public sector sees itself as a long term user of industry services and hence developing the construction industry and its people is considered significantly important. From this perspective prequalification systems can be seen as a mechanism to transform people within the construction industry. As such, governments can possibly use prequalification to drive various improvements for the industry and those that are serviced by it. This invariably creates a more productive and economically beneficial industry environment.

It was evident that public sector respondents viewed prequalification as significantly contributing to ongoing training and development within industry. This was said to be for both trade and professional skills, the latter being an area which is increasing in prominence. The major concern appeared to be with the abilities of small to medium sized business. These organisations and the people involved tend to make up the greater part of construction environment. As one public sector respondent put it, the construction industry has "got a long tail of very small businesses and a small number of very large businesses." It was said that prequalification had a strong emphasis on trying to improve the capabilities of small and medium businesses. Furthermore, a public sector prequalifier commented that prior to prequalification a lot of smaller businesses were failing because they might have been very good technically but they didn't have the basic management competencies. There seemed to be reasonable support from client sources that prequalification had reduced the failure rate in small to medium businesses. This area seems important yet was not reflected in past literature. The authors suggest that improving the skills of people in these businesses will lead to better outputs such as contractors that run profitable long term businesses.

Contractor responses in general were very supportive in respect to prequalification driving the development of their people. The proviso was that it had to be taken seriously as a broad management system rather than just a way for getting more work. One contractor said "It'll assist me or encourage me to invest a bit more here, to think strategically, to think more carefully about the people I employ, about the training and development of those people". It would appear that prequalification makes managers look more closely at their businesses. This extends to them introducing new systems and procedures and reviewing them as need be. It seems that prequalification can take some credit in respect to continuous improvement of staff and associated systems.

The issues of subcontractor capability and development were also raised. A public client respondent referred to subcontractors as the ones which are most vulnerable to failure due to a lack of management skills. He suggested that a system such as prequalification can put a framework around them, to help them, lift them and identify their issues. Unfortunately, it was found that subcontractor participation in prequalification was at very low levels. Past research did note that a problem existed with good contractors opting not to participate but this research indicates that low subcontractor participation seems to be the greater issue. The authors have gathered that the low participation rates in client systems seem to come from subcontractor apprehension, exclusion, general apathy or even collusion against taking part.

A positive output of prequalification was that once contractors became prequalified they took great pride in that fact and guarded their ratings very highly. This was mentioned by a public sector prequailfier. Hence, people working in the contracting field do derive substantial satisfaction from their achievement. Prequalification was also seen as having the potential to increase and promote professionalism within building organisations. These types of issues are worthy of consideration by both clients and contractors and were not found within the prequalification literature. Furthermore, both an architect and a contractor said that 
prequalification systems have reduced the traditional professional role of architects in the contractor selection process. Hence, it appears that prequalification systems may have contributed to diminished power and authority for architects within this area.

\section{Creativity and Innovation}

Prequalification systems were generally seen as being very rigid in nature with prospective contractors having to conform to them without reservation. It was said that such systems tend to stifle people putting ideas forward and shackles creativity at an early stage within construction projects. It was brought up by both client and contractor respondents as an issue of concern. Garnered perspectives showed two dimensions to this prequalification problem. One dimension concerned affording contractors creative flexibility and the other dimension allowing clients innovative freedom and some discretion. Both dimensions exist within the same boundary, the same environment.

Contractor creativity comes in the form of new ideas. As one private sector client put it "they might be offering a metre but they're only going to show you a millimetre". He went on to say that many contractors fear that if they present innovative ideas at the project prequalification stage this information will be passed onto other prospective contractors. Hence, contractors can be very guarded until they are assured of some return. It was said in the literature that a contractor's technical prowess could lead to innovative outcomes on site. Although this would be welcomed it was surmised from the findings that the benefits from innovative input could be more broadly harnessed. As such, early prequalification processes and discussions have to be structured in an appropriate way. Providing systems that develop trust creates a free flowing exchange of information allowing for possible design, production and economic benefits. This can only occur in a more flexible type of prequalification system where contractors are encouraged to present new ideas regarding specific projects. This could also foster feelings of project inclusiveness and "ownership" at an early stage.

The other dimension looks at providing client organisations with opportunities to be innovative. For example, there is within the industry client systems that "piggy-backed" off other more established prequalification systems. This means that if a contractor is already prequalified with a recognised system they may only need to respond to the client's more specific project requirements. A positive output easily identified is the reduction of burdensome prequalification workloads on people. The notion of prequalification "piggybacking" seems a novel approach although the literature did raise using a third party for prequalifications which could possibly deliver similar outcomes. Another novel idea as practised by a large public client was the pairing up of contractors via the prequalification process for projects. By giving contracting people opportunities to work in tandem it was found that they could actually synergise, develop and grow together. Organisational capability and economic benefits would appear to result. A further example of innovation involved a private sector client discussing a strategy of clients taking on greater risk. This was in regard to creating market tension by allowing emerging contractors in so as to develop these people. This suggests that clients and prequalifiers can actually influence their environment rather than just be influenced by it.

Flexible systems that encourage creativity and innovation are highly desirable and could produce improved project outputs. A public sector respondent commented that introducing some policy discretion into prequalification systems would assist.

\section{Conclusion}

The research found that prequalification systems are basically seen as a useful management system by industry practitioners. The process of evaluating contractors has been the main thrust of past thinking. This has involved clients sifting through the myriad of contractors on offer in any particular marketplace. However, there is another perspective of 
prequalification that has received little attention. That is one which highlights the greater human perspective. This paper has focused on this perspective.

The use of a soft systems approach and the in-depth interviewing of a wide range of experienced stakeholders were deemed beneficial. The stakeholders included clients, contractors and consultants which allowed for the fostering of alternative viewpoints. The research purposely set out to use soft systems ideology to stimulate broader thinking in respect to prequalification systems. This allowed for the identification and examination of the more human types of prequalification issues and a comparison of past researchers' findings to the current findings. The current findings were seen to have both positive and negative aspects but overall there seemed to be possibilities within building better relationships, creating more equitable systems, developing people and seeking improved creative solutions.

In conclusion, identifying the more human aspects presented by prequalification systems provides some useful insights for the construction industry. It is hoped that the findings serve to inform industry of the human ramifications attached to prequalification practices in the current environment. A better understanding in this area could improve the design of prequalification systems so that broader benefits could be realised from these systems.

\section{Acknowledgements}

The authors wish to express their gratitude to Dr. David Ness for his contribution to this research.

\section{References}

Al-Harbi, K. M. Al-S. (2001) 'Application of the AHP in Project Management', The International Journal of Project Management, 19 (1), 19-27

Bouma, G. D. and Ling, R. (2004) The Research Process, Fifth Edition, Oxford University Press

Checkland, P. (2000) 'Soft Systems Methodology: A Thirty Year Retrospective', Systems Research and Behavioural Science, 17 (1), 11-58

Cheng, E. W. L. and Li, H. (2004) 'Contractor Selection Using the Analytic Network Process', Construction Management and Economics, 22 (10), 1021-1032

Construction Industry Development Agency (CIDA) (1994) The Australian Construction Industry Prequalification Criteria for Contractors and Subcontractors, Sydney, NSW, 1-74

Daellenbach, H. G. (2003) Systems Thinking and Management Science, REA Publications

El-Sawalhi, N., Eaton, D. and Rustom, R. (2007) 'Contractor Prequalification Model: StateOf-The-Art', International Journal of Project Management, 25 (5), 465-474

Flick, U., von Kardorff, E. and Ines, S. (2004) A Companion to Qualitative Research, Sage Publications

Fontana, A. and Frey, J. H. (2003) 'The Interview: from Structured Questions to Negotiated Text', Collecting and Interpreting Qualitative Materials, $2^{\text {nd }}$ Edition, Editors: Denzin, N. K., Lincoln, Y. S., Sage Publications

Hickey, A. M. and Davis, A. M. (2003) 'Elicitation Technique Selection: How do Experts do it?' Requirements Engineering Conference, 11th IEEE International, 2003, 169-178

Holt, G. (2010) 'Contractor selection innovation: examination of two decades' published research', Construction Innovation: Information, Process, Management, 10 (3), 304-328

Jennings, P. and Holt, G. D. (1998) 'Prequalification and Multi-Criteria Selection: A Measure of Contractors Opinions', Construction Management and Economics, 16 (6), 651-660 
Lam, K. C., Hu, T. S. and Ng, S. T. (2005) 'Using the Principle Component Analysis Method as a Tool in Contractor Prequalification', Construction Management and Economics, 23 (7), 673-684

Latham, M. (1994) Constructing the Team, Final Report of the Government/Industry Review of Procurement and Contractual Arrangements in the UK Construction Industry, HMSO, London, 1-129

Li, S., Foulger, J. R, and Phillips, P. W. (2008) 'Analysis of the Impacts of the Number of Bidders Upon Bid Values: Implications for Contractor Prequalification and Project Timing and Bundling', Public Works Management and Policy, 12 (3), 503-514

Lo, W., Krizek, R. J. and Hadavi, A. (1999) 'Effects of High Prequalification Requirements', Construction Management and Economics, 17 (5), 603-612

Mangitung, D. M. and Emsley, M. W. (2002) Decision Criteria for Periodic Qualification in the UK Construction Industry, Manchester Centre for Civil and Construction Engineering, University of Manchester, Institute of Science and Technology, 1-14

Metcalfe, M. (2006) Reading Critically, Sage Publications, London

Mills, A. J. (2005) 'Client and Contractor Attitudes to Prequalification', American Association of Cost Engineers International Conference, New Orleans, 2005, 1-23

Minchin, R. E. and Smith, G. R. (2001) Quality Based Performance Rating of Contractors for Pre- qualification and Bidding Purposes - National Research Council, Pennsylvania State University, 1-9

Moore, N. (2000) How to do Research: The Complete Guide to Designing and Managing Research Projects, $3^{\text {rd }}$ Edition, Library Association Publishing

Ng, S. T. (2001) 'EQUAL: 'A Case Based Contractor Prequalifier', Automation in Construction, 10 (4), 443-457

Ng, S. T., Skitmore, M., R. and Smith, N. J. (1999) 'Decision-makers' Perceptions in the Formulation of Prequalification Criteria', Engineering Construction and Architectural Management, 6 (2), 155-165

Nga, S. T. and Luub, C. D. T. (2008) 'Modeling subcontractor registration decisions through case-based reasoning approach', Automation in Construction, 17 (7), 873-881

Ngai, S. C., Drew, D. S., Lo, H. P. and Skitmore, M. (2002) 'A Theoretical Framework for Determining the Minimum Number of Bidders in Construction Bidding Competitions', Construction Management and Economics, 20 (6), 473-482

Ogunsemi, D. R. (2006) An Evaluation of Contractors' Selection Criteria for Different Tendering and Procurement Methods in Nigeria, Australasian University Building Educators Association Conference, University of Technology - Sydney, 2006, 1-17

Palaneeswaran, E. and Kumaraswamy, M. M. (2000) 'Contractor Selection for Design/Build Projects', Journal of Construction Engineering and Management, A.S.C.E., 126 (5), 331-339

Palaneeswaran, E. and Kumaraswamy, M. M. (2005) 'Web-Based Client Advisory Decision Support System for Design-Builder Prequalification', Journal of Computing in Civil Engineering, ASCE, 19 (1), 69-82

Palaneeswaran, E., Ng, T. and Kumaraswamy, M. (2006) 'Client Satisfaction and Quality Management Systems in Contractor Organizations', Building and Environment, 41 (11), 1557-1570

Pongpeng, J. and Liston, J. (2003) 'Contractor Ability Criteria: A View from the Thai Construction Industry', Construction Management and Economics, 21 (3), 267-282

Prichard, R. G. (2000) 'Contractor Qualification', Retrieved from http://www.irmi.com/ expert/articles/2000/prichard08.aspx 
Russell, J. S. and Skibniewski, M. J. (1988) 'Decision Criteria in Contractor Prequalification', Journal of Management in Engineering, A.S.C.E., 4 (2), 148-164

Schoderbek, P. P., Schoderbek, C. G. and Kefalas, A. G. (1990) Management Systems, Conceptual Considerations, 4th Edition, BPI Irwin

Singh, D. and Tiong, R. L. K. (2005) 'A Fuzzy Decision Framework for Contractor Selection', The Journal of Construction Engineering and Management, 131 (1), 62-70

Skinner D., Tagg, C. and Holloway, J. (2000) 'Managers and Research: The Pros and Cons of Qualitative Approaches', Management Learning, 31 (2), 163-179

Sonmez, M., Holt, G. D., Yang, J. B. and Graham, G. (2002) 'Applying Evidential Reasoning to Prequalifying Construction Contractors', Journal of Management in Engineering, A.S.C.E., 18 (3), 111-119

Ticehurst, G. W. and Veal, A. J. (2000) Business Research Methods - A Managerial Approach, Longman

Topcu, Y. I. (2004) 'A Decision Model Proposal for Construction Contractor Selection in Turkey', Building and Environment, 39 (4), 469-481

Wong, H. C. (2004) 'Contractor Performance Prediction Model for the United Kingdom Construction Contractor: Study of Logistic Regression Approach', Journal of Construction Engineering and Management, A.S.C.E., 130 (5), 691-698

Wright, L. T. (1996) 'Exploring the In-depth Interview as a Qualitative Research Technique with American and Japanese Firms', Marketing Intelligence and Planning, 14 (6), 59-64

Zulauf, C. A. (2004) 'Systems Thinking: You Can Be More Proactive', Executive Excellence, $21(7), 13$ 